Manuelle Medizin 2018 $56: 239-248$

https://doi.org/10.1007/s00337-018-0405-6

Published online: 29 May 2018

(c) The Author(s) 2018

CrossMark

\author{
Wolfgang von Heymann ${ }^{1} \cdot$ Horst Moll ${ }^{2} \cdot$ Geraldine Rauch ${ }^{3}$ \\ 'Orthopädische Praxis, Bremen, Germany \\ ${ }^{2}$ Orthopädische Praxis, Leutkirch, Germany \\ ${ }^{3}$ Charité - Universitätsmedizin Berlin, corporate member of Freie Universität Berlin and Berlin Institute of \\ Health, Institute of Biometry and Clinical Epidemiology, Humboldt-Universität zu Berlin, Berlin, Germany
}

\title{
Study on sacroiliac joint diagnostics
}

\section{Reliability of functional and pain provocation tests}

grooves occur. The most frequent location of the ridges appears to be on the ilium. These ridges are not identical with osteoarthritis. However, the interdigitating symmetrical grooves and ridges [6] of the SIJ articular surfaces contribute to the highest coefficient of friction of any diarthrodial joint. This property enhances the stability of the joint against shearing [37]. The keystone-like bony anatomy of the sacrum further contributes to stability within the pelvic ring. At its base, the sacrum is wider superiorly than inferiorly; it is also wider anteriorly than posteriorly, permitting the sacrum to act like a "wedge" towards caudally and dorsally between the ilia within the pelvic ring. This anatomical structure of the sacrum in humans is adapted to resist shearing from vertical compression (e. g., gravity) and anteriorly directed forces on the spine. Therefore, in an upright position, the mobility is even more restricted and the total degree of mobility is less than $1^{\circ}[37]$.

Immediately after birth, the general orientation of the human SIJ is very similar to that of quadrupeds. The articular surfaces have the same angular orientation as the zygapophyseal joints of the lumbar vertebrae. Change begins as soon as the child starts to walk upright. The sacrum enlarges laterally, and the articular surfaces modify to a more complex adult curvature, resulting in the surface profiles of the joint bearing resemblance to a propeller-like shape. Comparative anatomical and paleontological research indicate that these changes are the result of mechanical factors, such as the supine position, body weight, load on the femur, and strain on the pubic symphysis [27].

Typically, the SIJ includes the sacral segments S1, S2, and S3, although inclusion of the complete S3 segment in the SIJ is not common for females [38]. In general, fusion of the sacral vertebra begins early in the second decade. The bony anatomy of the joint surface is highly variable in size, shape, and contour among individuals, and the shape of the joint changes markedly from infancy to adulthood [6]. The sacral auricular part is generally concave; however, often an intra-articular bony tubercle is present ventrally, in the middle aspect of the auricular surface of the sacrum. The iliac part is predominantly convex. Large variations of the auricular surfaces exist, resulting in intra-individual variations of motion axes.

The SIJ is unique in having elements of a combined synarthrosis and a diarthrosis-hence resulting in the term amphiarthrosis. The main portion of the joint is surrounded by a complex capsule and lined with cartilage (diarthrosis). Its shape is auricular, and "opens" posteriorly. The sacrum and ilia have an extracapsular, dorsally located articulation (synarthrosis), which is augmented by the vast iliosacral ligament (ISL) that provides considerable internal stability. Essentially, the SIJ is encased in a capsule that has a smooth anterior wall and irregular bands comprising the 
posterior wall. The capsule is innervated, at least from the dorsal lumbosacral rami (L5-S3) and is surrounded by several strong ligaments, such as the sacrotuberal ligaments, sacrospinal ligaments, long dorsal sacroiliac, and iliolumbar ligaments, which therefore influence its range of motion. In turn, these ligaments are related to a complex thoracolumbar fascia composite derived from the aponeuroses of several large muscles (like the paraspinal and the abdominal muscles) that surround the joint at a distance [37].

\section{Diagnostics of SIJ dysfunction}

What is meant by the "dysfunction" of a joint that has so little mobility? Currently, there are no data to prove one or the other hypothesis-is it really the very small mobility, is it the affection of the capsule, or is it just a soft tissue reaction in segmental connection with the SIJ? Therefore, we rely on observations of pain and restriction in the region of the pelvic girdle and the related connective tissues.

On the one hand, structural changes exist in the bony parts of the joint, the synovia, and the capsule, which are caused either by long-lasting mechanical overcharge in the sense of degenerative osteoarthritic changes altering the mechanics by osteophytes. Alternatively, pathological autoimmune-reactive processes (by inflammation) also lead to a structural change of the joint, in the most severe situation represented by a synostotic fusion (i.e., ankylosing spondylitis). These changes are not reversible. However, they only occur in a small proportion of patients with respective complaints. On the other hand, the vast majority of patients present a reversible dysfunction during the examination, which sometimes disappears spontaneously, but more often will dissolve only after external influence (mechanical, medication, etc.).

Similar to the intervertebral joints and using the forces of compression or distraction, these reversible dysfunctions have the property to react to a respective mechanical provocation with a diminution of pain in at least one direction.
The reversible SIJ dysfunction follows the pattern of a complex arthro-neuromuscular reaction as an answer to nociception [4]. This complex nocireaction comprises the segmentally organized muscles that show a painful protective contraction, as well as the vast ligamentous apparatus of the pelvis that will develop painful insertions (here from segments L5-S3).

Last but not least, the multilayered collagenous fibers have to reorient themselves according to the altered direction of mechanical load within the system of the deep fascia of the abdominal, back, and leg muscles. In addition, a densification of the fascial layers through physical forces or biomechanical processes will occur that reduces the gliding, with the result that a spontaneous return to normal function is impeded [28, 29].

Which changes occur in the joint itself? Even today, we can only answer this question hypothetically. Based on the abovementioned data, it is quite plausible that the grooves and ridges that form themselves individually in every person during upright walking on the corresponding surfaces will always move in the same way, they will follow a uniform pattern.

In case external influences disturb this pattern, the grooves and ridges will no longer fit, leading to a disturbance of the movement-perhaps similar to a train that has been derailed. We can usually influence this biomechanical part of the complex nocireaction by mobilizing the joint partners (sacrum and ilium) in a direction previously established to be painfree or just by separating them from each other.

The very successful manual therapeutic techniques to treat SIJ-related pain based on a reversible dysfunction that we teach today follow this hypothesis. Therefore, it is an indispensable precondition for treatment to differentiate between structural damage and reversible dysfunction by diagnostic steps, and furthermore to identify the pain-free direction of any movement in the latter. Although this sounds plausible, in daily practice it is not so easy.

Therefore, SIJ diagnostics remain difficult and uncertain. There is no typical pain pattern; there are substantial contradictions in the analysis of the innervation [10-12, 14, 24, 27]. Today, there is still no gold standard in SIJ diagnostics. Even $\mathrm{Rx}$ (fluoroscopically)-guided intraarticular injections do not have reliable results [9]. Many irritation zones/points have been described [5]. The clinical examination of function is not reliable and reproducible $[21,25,26]$. In addition, we have to take into consideration that the perception of pain at a certain point of the anatomy does not mean that the nocigenerator of this pain is exactly where the brain locates that pain. This means that a chronic pain in the area of the SIJ may also be a referred pain of any nocigenerator in any structure segmentally innervated from L5 to S3 [23]. Is there reliable information from the clinical findings at all? In this respect, the publications are conflicting and not unanimous $[2,8,13$, 19, 20, 32-34, 40]. Nevertheless, these studies present some general ideas:

- Not reliable are:

- One single test

- An inexperienced examiner

- SIJ pain combined with low back pain (LBP)

- Reliable are:

- At least three pain tests with the same result

- An experienced examiner

- Gluteal pain, also pseudo-radicular leg pain

- Good positive or negative pre-test probability

- Pain provocation is more reliable than palpation of mobility

The real functional mobility of the SIJ in a supine position is a complex threedimensional nutation and counternutation movement of the sacrum towards the ilium in the range of $2-4^{\circ}$. This can only be tested in a lying position, using a helicoidal axis that varies largely even between the SIJs of the same person [3].

The axis even depends on the actual function (standing on both or one leg, lying in supine or prone position; [15]). During the nutation, the base of the sacrum moves cranially and anteriorly, and during counternutation, the tip of the sacrum moves caudally and anteriorly. During aging, the mobility 
Manuelle Medizin 2018 · 56:239-248 https://doi.org/10.1007/s00337-018-0405-6

(c) The Author(s) 2018

W. von Heymann · H. Moll · G. Rauch

\section{Study on sacroiliac joint diagnostics. Reliability of functional and pain provocation tests}

Abstract

Background. As there is currently no gold standard for the diagnosis of SIJ dysfunction, a broad variety of tests exist to clinically identify pelvic girdle pain caused by reversible SIJ dysfunction. Some of the pain provocation tests have already been evaluated. However, the tests used by the majority of German physicians competent in manual medicine (MM) have not yet been evaluated. Therefore, such an evaluation is necessary.

Objective. The aims of the study were to evaluate the reliability of functional and pain provocation tests used in SIJ diagnostics, and to propose a useful set of reliable tests.
Methods. Two raters investigated 161 subjects (81 symptomatic with low back pain, 80 asymptomatic controls) in a blinded setting, each with a set of three functional and six pain provocation tests. Three of the pain provocation tests had already been evaluated and these were used for comparison with the non-evaluated tests.

Results. The Cohen's kappa coefficients of the newly evaluated tests were better $(\kappa=0.76-1.00)$ than those of the previously evaluated tests $(\kappa=0.65-0.89)$. The functional tests had a lower $\mathrm{K}$-coefficient and an overly wide confidence interval $(\mathrm{Cl})$, and were thus evaluated as being not reliable and only suitable as screening tests.

Conclusions. The pain provocation tests, which use palpable irritation deep in the gluteal muscles with provocation in two planes, are at least as reliable as the already evaluated tests. We recommend adding SIJ irritation point diagnostics to the set of " 3 out of 5 positive pain provocation tests" for safe diagnosis of SIJ dysfunction.

Keywords

Low back pain $\cdot$ Pelvic girdle pain · Manual therapy · Reproducibility of results · Palpation

\section{Diagnostik von Dysfunktionen des Sakroiliakalgelenks. Studie zur Reliabilität von Funktions- und Schmerzprovokationstests}

\section{Zusammenfassung}

Hintergrund. Da es bisher keinen Goldstandard zur Diagnostik einer Funktionsstörung des Sakroiliakalgelenks (SIG) gibt, existiert ein großes Angebot an Tests, um klinisch eine reversible SIG-Dysfunktion als Ursache von Beckengürtelschmerzen zu identifizieren. Einige Schmerzprovokationstest wurden bereits evaluiert. Eine Prüfung der Tests, die von der Mehrheit der deutschen Manualmediziner genutzt werden, ist jedoch noch nicht erfolgt. Ziel der Studie. Ziel waren die Evaluation der Reliabilität von Funktions- und Schmerzprovokationstests, die für die SIG-Diagnostik verwendet werden, und der Vorschlag eines zuverlässigen Testsets.
Methodik. Zwei Untersucher prüften verblindet 161 Probanden (81 symptomatisch mit Kreuzschmerzen, 80 asymptomatisch) mit jeweils 3 Funktions- und 6 Schmerzprovokationstests. Bereits evaluiert sind 3 der Schmerzprovokationstest; sie wurden mit den noch nicht evaluierten verglichen.

Ergebnisse. Die Ergebnisse der CohensKappa-Koeffizienten der neu evaluierten Test waren besser $(\kappa=0,76-1,00)$ als die der bereits früher evaluierten $(k=0,65-0,89)$. Die Ergebnisse für Funktionstests zeigten niedrigere $\mathrm{k}$-Koeffizienten und zu breite Konfidenzintervalle; daher sollten diese allenfalls als Screeningtests verwendet werden.
Schlussfolgerungen. Die Provokationsschmerztests, die die Irritation der tiefen Glutealmuskulatur mit einer Provokation in 2 Dimensionen verwenden, sind mindestens so zuverlässig wie die bereits evaluierten Vergleichstests. Wir empfehlen daher, die Irritationspunktdiagnostik in das Testset „3 aus 5 Provokationstests positiv“ aufzunehmen, um eine SIG-Dysfunktion sicher zu diagnostizieren.

\section{Schlüsselwörter}

Unterer Rückenschmerz · Beckengürtelschmerzen - Manuelle Therapie . Reproduzierbarkeit von Ergebnissen. Palpation decreases in men. In young subjects and in the horizontal position of the body we find $4^{\circ}$, in older men only $2^{\circ}$.

With only $2-4^{\circ}$ of three-dimensional mobility in a supine position and less than $1^{\circ}$ in an upright position, it is very difficult to produce clinically reliable signs of articular movements. In fact, clinical manual movement tests are completely unreliable for the SIJ [39]. Commonly used diagnostic tests are 1. the standing-flexion test (also called bending-forward-test or Gillet-test or Piedallu-test) and 2. the spine-test (also called hip flexion test or stork-/flamingotest). Unfortunately, these tests have low reliability [22] and low reproducibility [21]. Sturesson et al. checked these tests in 22 patients with severe SIJ pain using radio-stereometric analysis (RSA). The results show minimal change of movements during the test, and no differences between symptomatic and asymptomatic sides. When the pelvis is loaded in a oneleg standing position while flexing the contralateral leg, patients are physically challenged, which leads to bilateral increased force closure of the SIJ [1, 3, 30]. During this test, no SIJ motion occurs. The visibly changing position of bony landmarks like the upper posterior iliac spine (SIPS) that is apparently derived from the SIJ is in fact a movement of the external pelvis relative to the hips. This gives the manually perceived but misleading illusion that the SIJs are moving [30]. Perhaps these functional tests react positively in the presence of SIJ dysfunction by changing the behavior of the connective tissues of the whole pelvic girdle.

\section{Study aim and design}

Several studies have checked the reliability of SIJ tests. In general, pain provocation tests seem to be more reliable than functional tests in the diagnosis of SIJ 


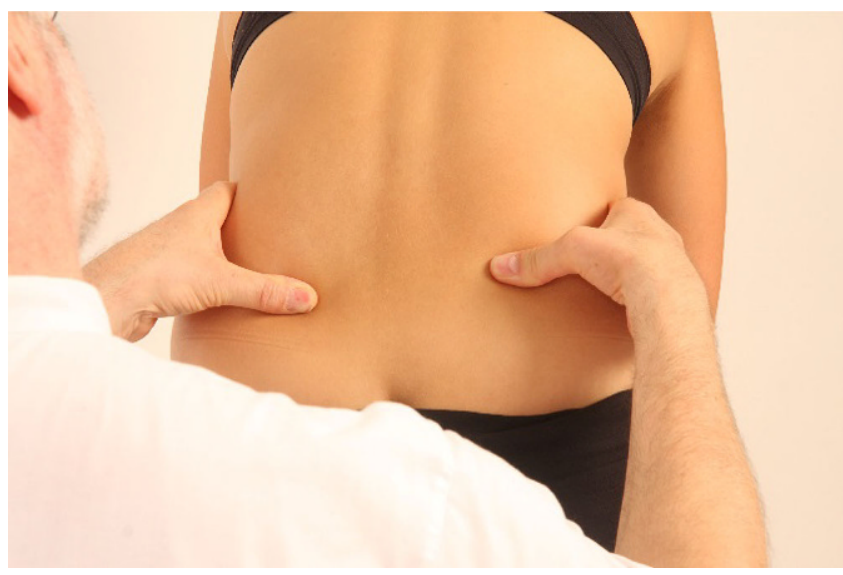

Fig. $1 \Delta$ Standing-flexion test: both examiner's thumbs pressed to the upper posterior iliac spine the subjects bends forward-check for asymmetrical movement of the thumbs. With kind permission of J.-M. Werner

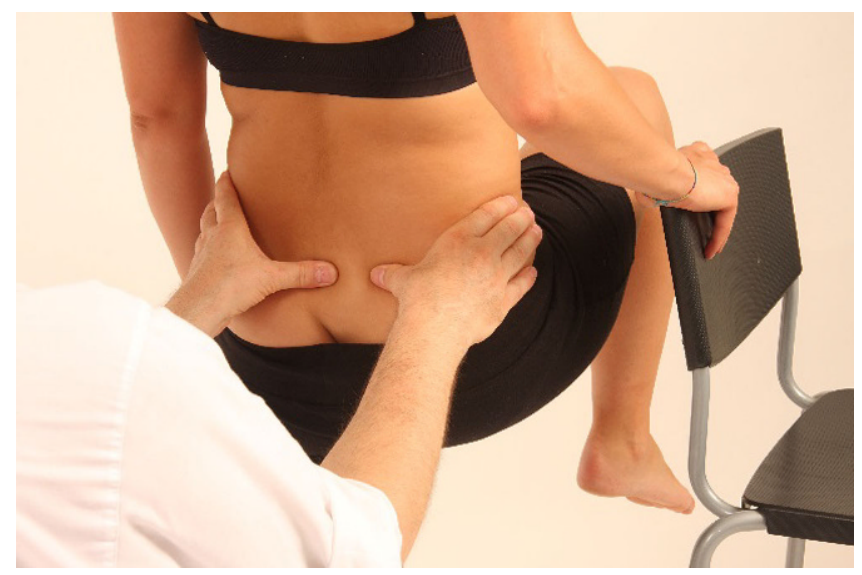

Fig. 2 S Spine-test: one examiner's thumb pressed to the upper posterior iliac spine, the other to the sacral crest, the subject flexes his leg on that side up to $90^{\circ}$; for free function of the SIJ, the iliac thumb should move downwards. With kind permission of J.-M. Werner dysfunction without structurallesion [35, 39]. The most frequently used tests are the compression test, the femur-thrust test, the pelvic torsion test, the FAbER test (for flexion, abduction, and external rotation; [17]), and the hip extension test [35]. Based on this specific differential diagnosis, the results of manual therapy for SIJ-related gluteal and leg pain in a prospective single-blinded trial were better $(72 \%$ success) than those of injections $(50 \%)$ or physiotherapy $(20 \%$; [36]).

In Germany, physicians have been competent in the use of manual medicine (MM) and have been teaching the method for 65 years. They have developed these tests through empirical observations and good practical results. Nobody has ever evaluated these tests in comparison to other diagnostic techniques. Therefore, in the world of evidence-based medicine and reliability studies, evaluation of these tests in comparison to each other has become inevitable. The described approach uses three steps to identify SIJ dysfunction, including an exact medical history and a neurological examination:

1. Check for articular mobility (M; supposedly unreliable),

2. Check for articular painful irritation points (I; supposedly quite reliable)

3. Functional pain provocation of irritation points ( $\mathrm{P}$; supposedly highly reliable)
This is a diagnostic study with the primary aim of evaluating the interrater reliability between two independent examiners with respect to the principles of the three-step diagnosis. The secondary aim was to evaluate the validity of the three-step diagnosis compared to the already evaluated SIJ testing procedures (here: FAbER test, pelvic torsion test, femur-thrust test). In the case of the two pain provocation tests of the Physicians' Seminar for Manual Therapy of Spinal and Periperal Joints (MWE; checking a gluteal irritation point for pain-free direction cranial-caudal and ventral-dorsal) reaching sufficient reliability in Cohen's kappa [7], these two tests were to be added to the set of tests, reaching a set of five tests that are reliable for SIJ diagnostics.

\section{Methods}

\section{Patient recruitment and rationale for sample size}

Recruitment of a total of 75 cases and 75 additional controls was planned.

- The symptomatic subjects were recruited from patients who came to a back pain rehabilitation clinic for a 3-week inpatient treatment because of chronic low back pain, not all had an SIJ dysfunction.

- The healthy subjects (controls) were recruited from physicians attending MM courses; not all of them were really completely without signs and symptoms of dysfunction.

The sample size was chosen to provide reasonable accuracy for estimation of the kappa coefficient. In the planning stage, it was expected that the level of agreement would be higher than 0.65 , i.e., almost perfect. The kappa value is calculated as $\mathrm{k}=(\mathrm{p} 0-\mathrm{pc}) /(1-\mathrm{pc})$, where $\mathrm{p} 0$ is the total agreement rate and $\mathrm{pc}$ the random agreement rate for a given cross-table. As we assume equal numbers of pathological and neutral cases, $\mathrm{pc}$ is expected to be 0.5 . As a consequence, for $\kappa=0.65$, it follows that $\mathrm{p} 0$ would be 0.825 . The estimated standard deviation (SD) is given by $\mathrm{SD}(\mathrm{k})=\sqrt{ }\left(\mathrm{p} 0(1-\mathrm{p} 0) /(1-\mathrm{pc})^{\wedge} 2\right)$. For a kappa value of 0.65 , the expected SD is thus 0.76 . The two-sided $95 \%$ confidence interval (CI) for Cohen's kappa coefficient is given as $\left[\mathrm{k}-1.96{ }^{*} \mathrm{SD}(\mathrm{k}) / \sqrt{\mathrm{n}}\right.$; $\mathrm{k}+1.96 * \mathrm{SD}(\mathrm{k}) / \sqrt{ } \mathrm{n}]$. For a total number of 150 subjects (75 cases, 75 controls) the expected $95 \%$ CI will thus be given by $[0.53 ; 0.77]$. Therefore, we planned to recruit at least 150 subjects, which seems sufficient and reasonable for evaluation of interrater reliability.

During the recruitment phase, we were finally able to recruit 161 participants ( 80 healthy subjects, 81 with low back pain or pelvic girdle problems). 


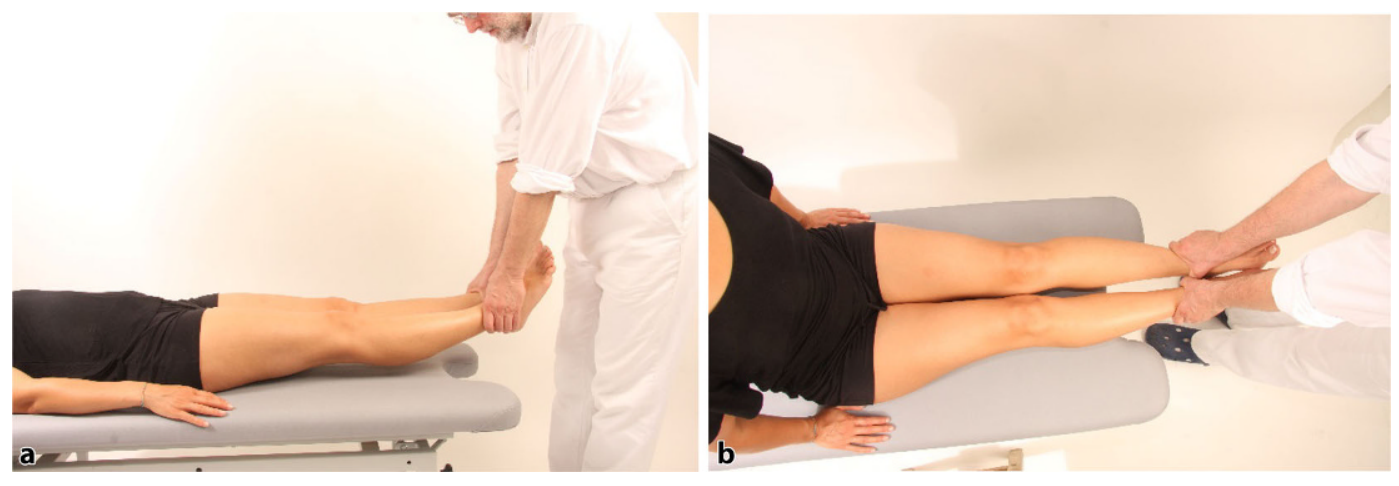

Fig. $3 \Delta$ Variability of leg length. a view from the side: start position with the subject lying supine, the legs of the subject are slightly lifted to have no contact with the table, $\mathbf{b}$ view from above: after the subject achieved the sitting position, the thumbs of the examiner should remain on the same level as in the lying position; if not, the test is registered as "positive ". With kind permission of J.-M. Werner
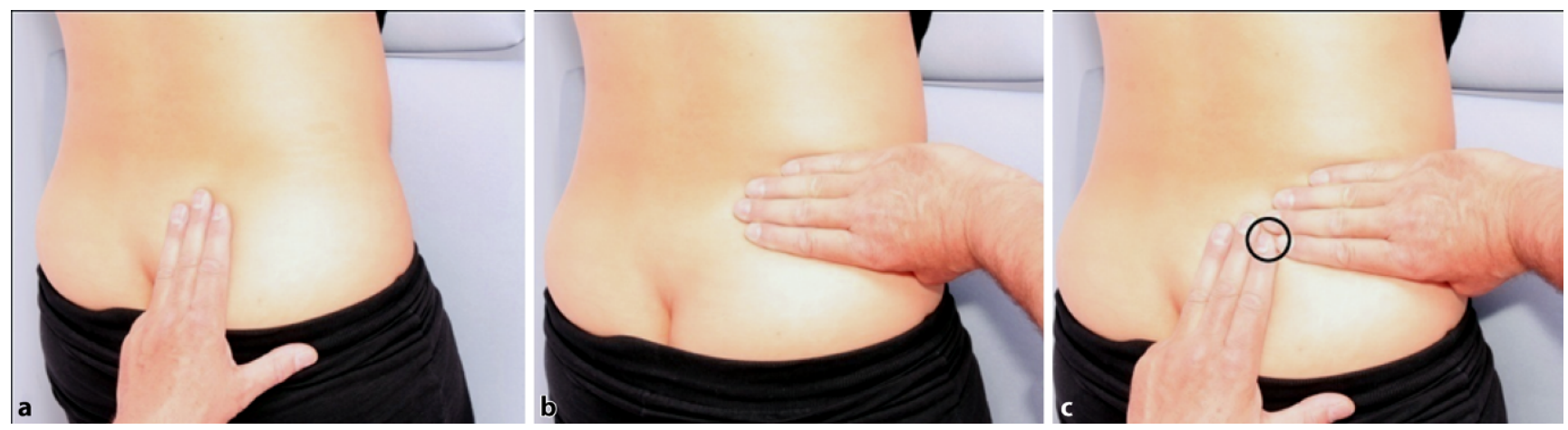

Fig. $4 \Delta$ Access "A" to SIJ-irritation. a Three finger withs laterally of the medial iliac rim, b four finger withs below the iliac crest, $\mathrm{c}$ the meeting-poiunt of the indexes is the point of the irritation. With kind permission of J.-M. Werner

\section{Diagnostic procedures}

The two raters have both been teaching MM for more than 3 years with the same approach, so there was a short formation of only one weekend. The almost perfect overall agreement in the formation period was established during an educational course for teachers acting as instructors in MM. There were 46 participants (all physicians), who were investigated by the two raters.

The inclusion criteria were an age between 18 und 60 years, a body mass index (BMI) between 18 and $30 \mathrm{~kg} / \mathrm{m}^{2}$, no radicular compression signs from L 5 or S1. The subjects were assigned at random as either patients or controls, waiting outside of the two separated examination rooms for the next free rater. They were examined at random first by either rater 1 or by rater 2 . In addition, the raters changed the sequence of tests at random to avoid the bias of the subjects expecting the same sequence. The two raters investigated all included subjects. Blinded to each other, they checked the subjects in a short time using a set of 10 diagnostic tests (one test was used in two versions), i.e., they finalized both examinations with a difference of less than $5 \mathrm{~min}$. No treatment was applied. There was no follow-up.

The 10 tests:

1. Standing forward flexion test (also called Piedallu test, "Vorlaufphänomen"): the subject standing upright, the examiner fixates both posterior upper iliac spines (SIPS), the subjects bends forward; any development of asymmetry of the SIPS' positions is registered as a positive (pathological) sign (• Fig. 1).

2. Spine test (also called Gillet test, stork/flamingo test): the subject standing upright, one hand supported, the examiner fixates on the side to be tested the PSIS with one thumb and with the other thumb the sacral crest. During bending the leg of that side in hip and knee over $90^{\circ}$, the thumb on the SIPS should move caudally in normal function (• Fig. 2).

3. Variability of leg length (also Derbolowsky test, sit-up test): the subject lying in supine position, the examiner takes both ankles with his hands, the thumbs in the same height at the ankle (- Fig. 3a); the subject then sits up with eyes closed and no contact between the teeth; any developing asymmetry of the "length" of the legs is registered as a positive (pathological) sign (• Fig. 3b).

4. Irritation point $A$ : the subjects lying relaxed in prone position, the examiner presses on both sides the indexes in projection to the gluteal muscles, with the exact point to be found three finger-widths laterally of the SIJ (• Fig. 4a), four finger-widths below the iliac crest (- Fig. 4b). At the meeting point 

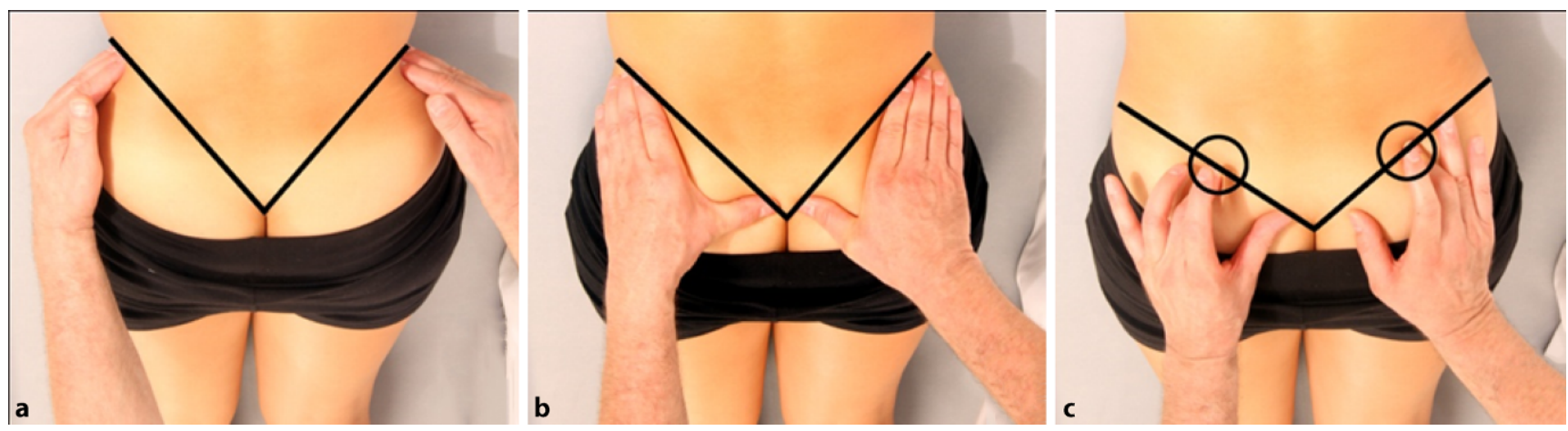

Fig. $5 \Delta$ Access " $B$ " to SIJ-irritation. a position the middle fingers on the upper lateral iliac crest, $\mathbf{b}$ position the thumbs to the cranial end of the anal cleft, $c$ bisecting the lines between middle finger and thumb you may find the SIJ-irritation bilaterally. With kind permission of J.-M. Werner

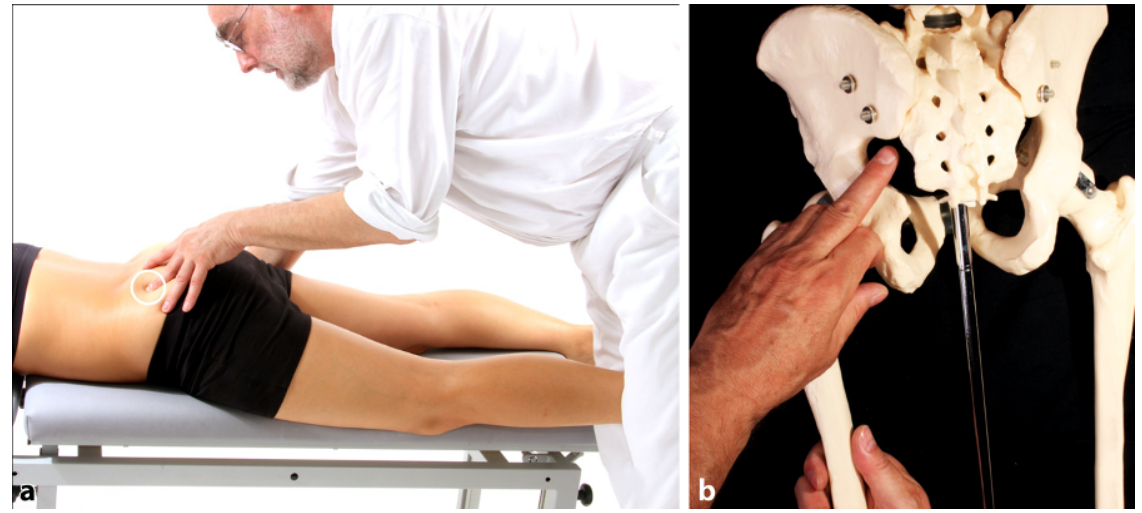

Fig. $6 \Delta$ Check for pain-free direction cranial-caudal. a The middle finger on the irritation, the subject's leg is tract down (nutation) or pushed upwards (counternutation) at the ankle between the examiners thighs, $\mathbf{b}$ position of the middle finger in relation to the pelvic bones. With kind permission of J.-M. Werner

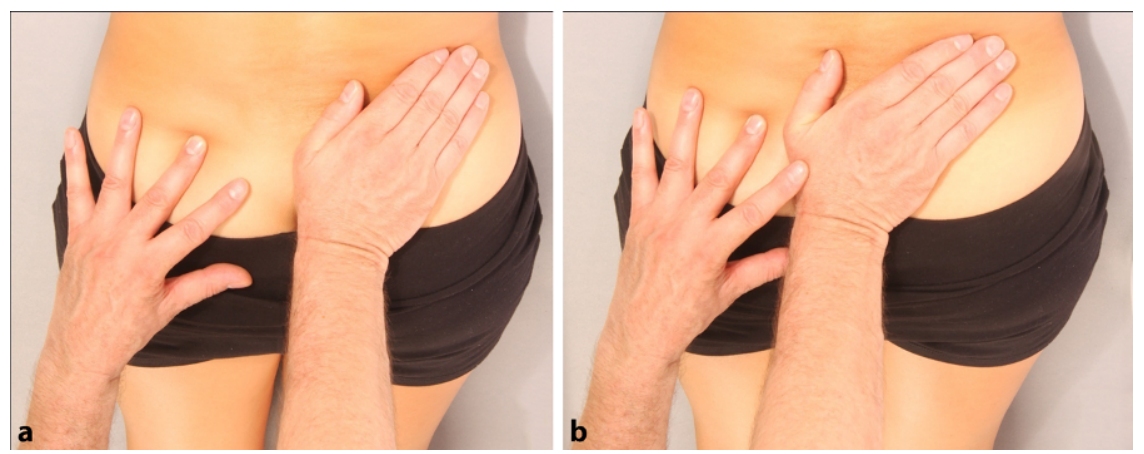

Fig. 7 A Check for pain-free direction ventral-dorsal. a With the middle finger to the irritation, compression to the ilium will provoke a counternutation direction, $\mathbf{b}$ compression to the sacral base (S1) will provoke a nutation direction. With kind permission of J.-M. Werner

of the index fingers, the irritation point is expected (• Fig. 4c). Any asymmetry in tissue consistency and pain is registered as a positive (pathological) irritation.

5. Irritation point $B$ : the subjects lying relaxed in prone position, the examiner presses on both sides the indexes in projection to the gluteal muscles. He finds the exact point by dividing in two the distance between the upper end of the anal cleft and the lateral edge of the iliac crest (- Fig. 5a, b). Any asymmetry in tissue consistency and pain is considered as a positive (pathological) irritation (• Fig. 5c).

6. Functional pain provocation in horizontal (frontal) plane of the lying subject: traction of the leg caudally (patient's ankle between physician's thighs) will induce a nutation movement of the sacrum; the reaction is checked at the positive irritation point (4 and/or 5). The examiner registers an increase or decrease of tension and pain at the irritation point. Pushing the leg to cranial direction will indicate the reaction to a counternutation movement of the sacrum (• Fig. 6a, b).

7. Functional pain provocation in vertical (sagittal) plane of the lying subject: compression to the sacral base (S1) will activate a nutation movement; compression to the tip of the sacrum (S5) will activate a counternutation movement. These directions of intraarticular forces will give information to the palpating finger at the irritation point, indicating a painful or painfree direction of articular function provocation (- Fig. 7a, b).

8. Flexion abduction external rotation test (FAbER test; also called sign of the 4 or Patrick test): with the subject lying in supine position, the examiner lays the lateral ankle of the side to be tested at the level of the patella of the opposite leg; he fixates the pelvis with one hand to the opposite anterior superior iliac spine (ASIS) and presses the ipsilateral knee towards the table. 


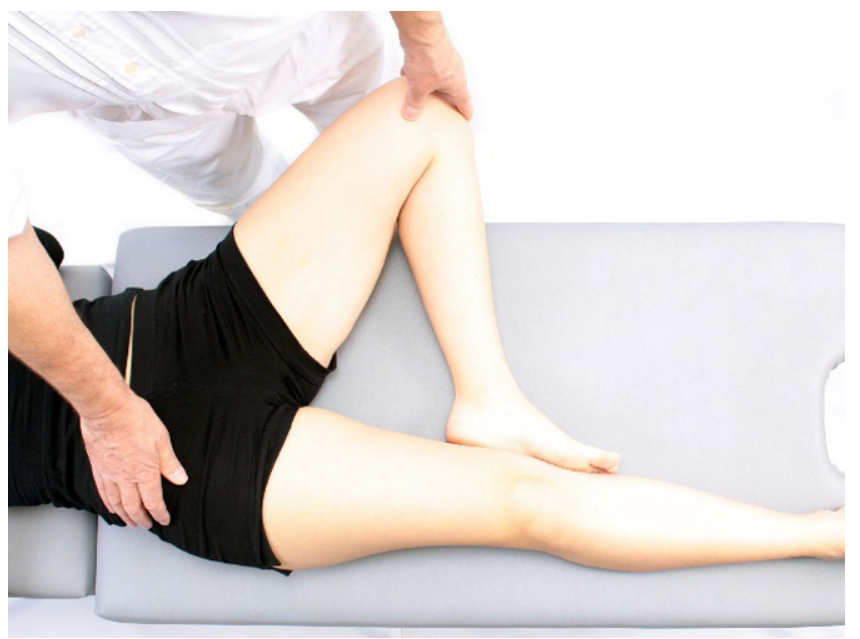

Fig. $8 \Delta$ FAbER-test: the ankle of the side to be tested on level of the opposite patella, the hip is in flexion, abduction, external rotation; the pelvis is fiexed on the opposite side, the end-feel is tested. With kind permission of J.-M. Werner

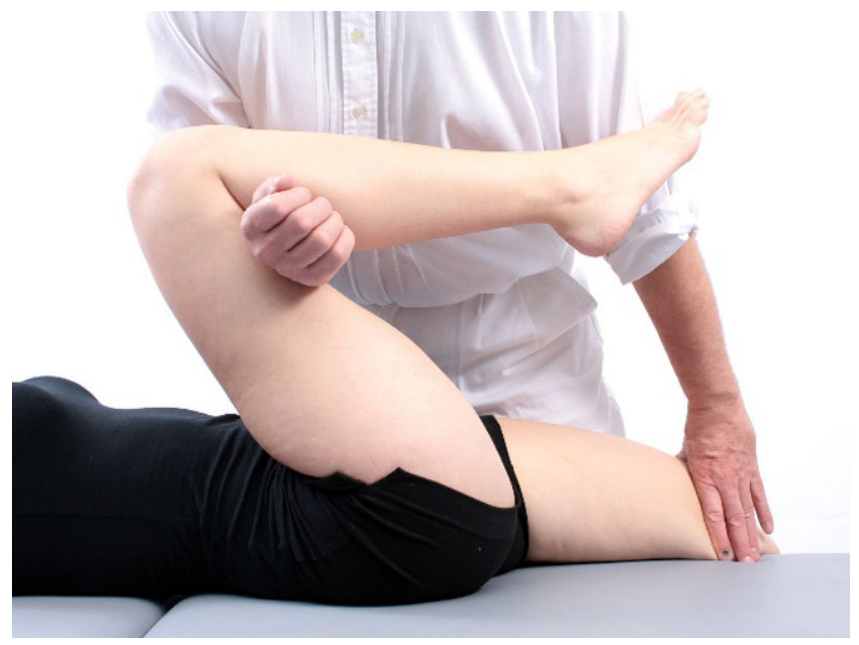

Fig. $9 \Delta$ Pelvic torsion test: one leg is positioned laterally of the table in hip extension, the other leg is flexed as much as possible in the hip; check for pain. With kind permission of J.-M. Werner
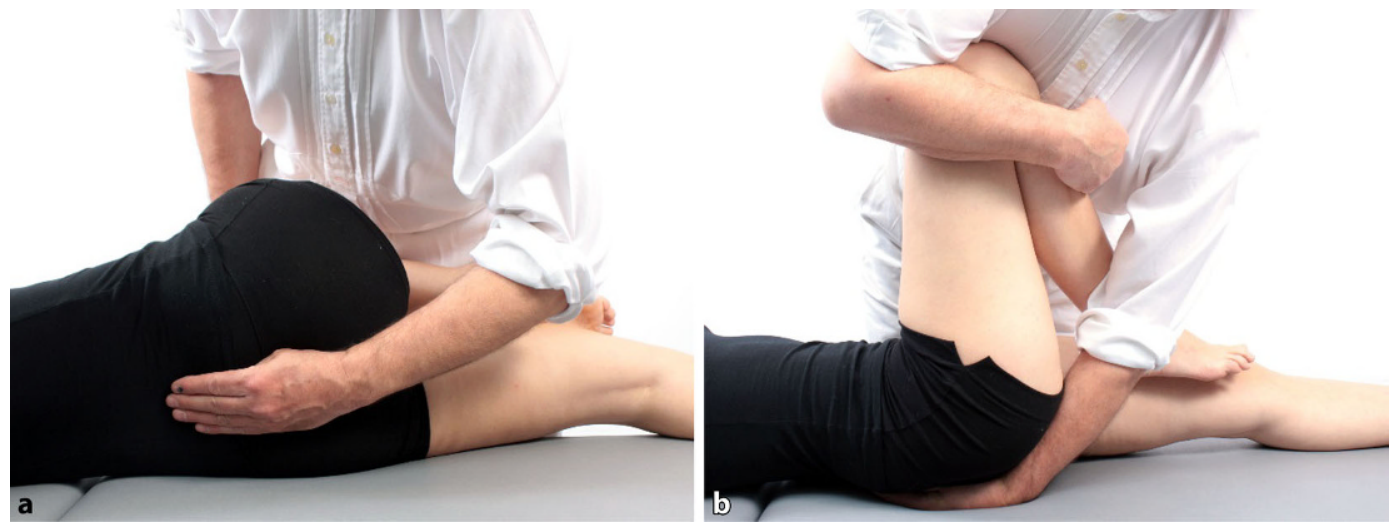

Fig. $10<$ Femur-thighthrust. a The examiners contracted thenar is positioned exactly under the sacrum, $\mathbf{b}$ with the weight of his body the examiners thrusts the subject's knee/ femur in the direction of his hand. With kind permission of J.-M. Werner

As the test also reacts to hip pain and its osteoarthritic stiffness, the degree of flexion, abduction, and external rotation is not important. Only the pain in the region of the sacroiliac joint counts for SIJ pathology (• Fig. 8).

9. Pelvic torsion test (also called Gaenslen test): with the subject lying in supine position just on one edge of the table, the examiners positions this side's leg besides the table in an extension position of the hip; then he bends the other leg in hip and knee as much as possible. After checking for pain in the sacral region, the test is repeated in the other direction of pelvic torsion from the other side of the table (• Fig. 9).
10. Femur-thigh thrust (also called Ostgaard test or $4 \mathrm{P}$ test $=$ posterior pelvis pain provocation test): with the subject lying in supine position, the examiner bends the leg opposite to him $90^{\circ}$ in the hip and rolls the pelvis to his side, so he can position one hand's contracted thenar under the sacrum, leaving the ilium free (- Fig. 10a). Then he rolls the pelvis back to a vertical position of the femur and gives with the weight of his body a thrust to the knee in direction of the own hand under the sacrum (• Fig. 10b). After registering "pain" or "no pain" in the region of the SIJ, he will repeat the test with the other femur.

\section{Statistical analysis strategy}

All analyses were performed for each diagnosed and evaluated side (right, left) separately. The interrater agreement for the three-step diagnostic approach was evaluated by means of Cohen's kappa coefficient along with a corresponding 95\% CI. Cohen's kappa coefficients were also calculated for each of the established tests separately. Sensitivity and specificity for the three-step diagnostic approach in comparison to several well-established tests were not evaluated separately, as the number of positive diagnoses was too small, especially for the left side. Nevertheless, the result of the diagnostic procedure was defined as positive if at least three of the five established tests (irritation point craniocaudal, irritation point ventrodorsal, FAbER test, Gaenslen test, 
Table 1 Cohen's kappa coefficients of the specific sacroiliac joint (SIJ) diagnostics; $\mathrm{K}$-values and 95\% confidence interval $(\mathrm{Cl})$ ranges

\begin{tabular}{|c|c|c|c|c|}
\hline & Right SIJ & Right SIJ & Left SIJ & Left SIJ \\
\hline & Cohen's k & $95 \% \mathrm{Cl}$ & Cohen's k & $95 \% \mathrm{Cl}$ \\
\hline $\begin{array}{l}\text { Forward flexion } \\
\text { (Piedallu) }\end{array}$ & $0.68 \pm 0,089$ & $0.51 ; 0.85$ & $0.41 \pm 0.13$ & $0.16 ; 0.66$ \\
\hline $\begin{array}{l}\text { Spine test } \\
\text { (Gillet test) }\end{array}$ & $0.53 \pm 0.090$ & $0.35 ; 0.71$ & $0.59 \pm 0.12$ & $0.35 ; 0.83$ \\
\hline $\begin{array}{l}\text { Variable leg length } \\
\text { (sit-up test) }\end{array}$ & $0.64 \pm 0.08$ & $0.48 ; 0.80$ & $0.71 \pm 0.07$ & $0.57 ; 0.85$ \\
\hline Irritation point (A) & $0.96 \pm 0.02$ & $0.96 ; 1.00$ & $1.00 \pm 0.00$ & - \\
\hline Irritation point (B) & $0.86 \pm 0.04$ & $0.80 ; 0.94$ & $0.75 \pm 0.08$ & $0.59 ; 0.91$ \\
\hline $\begin{array}{l}\text { Pain provocation } \\
\text { Cranial-caudal }\end{array}$ & $0.76 \pm 0.06$ & $0.64 ; 0.88$ & $0.89 \pm 0.06$ & $0.87 ; 0.99$ \\
\hline $\begin{array}{l}\text { Pain provocation } \\
\text { Ventral-dorsal }\end{array}$ & $0.93 \pm 0.03$ & $0.87 ; 0.99$ & $0.86 \pm 0.07$ & $0.72 ; 1.00$ \\
\hline $\begin{array}{l}\text { FAbER test } \\
\text { (Patrick/sign of 4) }\end{array}$ & $0.73 \pm 0.11$ & $0.51 ; 0.95$ & $0.34 \pm 0.19$ & $0.00 ; 0.71$ \\
\hline $\begin{array}{l}\text { Pelvic torsion test } \\
\text { (Gaenslen test) }\end{array}$ & $0.65 \pm 0.16$ & $0.34 ; 0.96$ & $0.39 \pm 0.28$ & $0.00 ; 0.94$ \\
\hline $\begin{array}{l}\text { Femur-thigh thrust } \\
\text { (4P test) }\end{array}$ & $0.89 \pm 0.04$ & $0.81 ; 0.97$ & $0.89 \pm 0.06$ & $0.77 ; 1.00$ \\
\hline
\end{tabular}

and the $4 \mathrm{P}$ or femur-thrust test according to Ostgaard) showed a positive result.

\section{Results}

Generally, the magnitude of Cohen's kappa coefficients for the agreement of the two raters is interpreted as follows: kappa values between 0 and 0.20 indicate poor agreement, values between 0.21 and 0.40 indicate sufficient agreement, values between 0.41 and 0.6 are interpreted as a substantial agreement, and kappa coefficients above 0.61 are interpreted as almost perfect agreement [16].

Although 168 subjects signed the informed consent to participate, 7 had to be excluded from evaluation as they did not fulfill the inclusion criteria, mainly because they were too old or too heavy. Of the included subjects, 82 (50.9\%) were male, $79(49.1 \%)$ were female. The mean age was $44.4 \pm 8.9$ years, the mean weight was $76.3 \pm 13.4 \mathrm{~kg}$, the mean height was $174.6 \pm 10.0 \mathrm{~cm}$, and the mean BMI was $24.8 \pm 3.1 \mathrm{~kg} / \mathrm{m}^{2}$. The general physical examination found in 3 (1.9\%) subjects a pathologic condition in the central nervous system, 9 (5.6\%) with cardiac problems (high blood pressure), 2 (1.2\%) with asthma, $1(0.6 \%)$ with nephrologic problems, $11(6.8 \%)$ had previous gastric ul- cular irritation. All results are compiled in $\bullet$ Table 1.

These results show that SIJ diagnosis using the gluteal irritation in combination with the pain provocation in the cranial-caudal plane as well as in the ventral-dorsal plane have an almost perfect kappa coefficient and are even more reliable than the already examined tests.

We accepted the precondition [18] that there is a need for at least three positive tests out of five for the diagnosis of SIJ dysfunction. Using the pain provocation test cranial-caudal, pain provocation test ventral-dorsal, FAbER test, pelvic torsion test, and femur thrust test, the interrater reliability for one of the possible three diagnoses (no SIJ dysfunction, dysfunction right SIJ, and dysfunction left SIJ) was evaluated:

- No SIJ dysfunction (80 subjects):

Cohen's $\kappa=0.93 \pm 0.03$; $95 \%$ CI [0.87; 0.99]

- Right-side SIJ dysfunction (61 subjects): Cohen's $\kappa=0.95 \pm 0.03 ; 95 \% \mathrm{CI}$ [0.89; 1.00]

cers, and 11 (6.8\%) had thyroid disorders. of them used the respective medication to control their specific problems.

In $8(5.0 \%)$ subjects there were signs of some nerve root compression, but none from the lumbosacral region, so they were not excluded. Another 31 (19.3\%) showed signs and symptoms of intervertebral dysfunction in the segments T12 to L5, which was also not a criterion for exclusion.

For the three functional tests (standing forward flexion, spine test, and checking the variability of leg lengths), we did not expect good results for interrater agreement. They are not based on real mobility within the SIJ, but rather on connective tissue reactions. Therefore, they may probably but not reliably be related to SIJ dysfunction. Although the observed kappa values were not poor for each of these functional tests, the $95 \%$ CI was too wide to allow an appropriate interpretation. Nevertheless, the observed kappa values for the FAbER test and the pelvic torsion test were almost equal to the data from the references [18]. In our study, we only found similarly good and precise results for the femur-thigh thrust as for the pain provocations to the gluteal mus-
- Left-side SIJ dysfunction (20 subjects): Cohen's $\kappa=0.94 \pm 0.04 ; 95 \% \mathrm{CI}$ [0.86; 1.00]

\section{Discussion and conclusion}

\section{Limitations}

The study is limited to a group of inpatients supposed to be impaired and to a group of physicians supposed to be healthy subjects. However, there is no evidence that these groups react differently than other patients or other healthy controls. There was no treatment at all and no follow-up to check the reliability of the diagnoses by post-therapeutic outcome.

Although the study was designed as a blinded study regarding the allocation of the subjects to the raters, some symptomatic subjects tried to start a discussion with the raters to get more information about themselves. Therefore, it was easy for the raters to uncover the respective allocation. As there were also many symptomatic subjects among the "controls" and almost the same number of asymptomatic subjects among the "patients," we estimate this bias to be neg- 
ligible. As both groups presented both results regarding the SIJ, the raters had to examine each subject without predisposition.

The number of subjects included was not as high as necessary for sufficient evaluation of a left SIJ pathology. The relation between symptomatic right-side and the symptomatic left-side SIJ dysfunction confirmed the empiric observation that the dysfunction of the right SIJ occurs much more often in our population (4:1) than the left SIJ. Unfortunately, the sensibility and specificity could not be evaluated reliably, because of the small number of positive diagnoses for the left side. Nevertheless, the model " 3 out of 5 positive pain provocation tests" has already been evaluated with an estimated sensitivity of $93.8 \%$ and a specificity of $78.1 \%$ [18].

Regarding the evaluated manual tests, only the most commonly used tests of one physicians' association for MM were investigated. However, the implementation of all other manual diagnostic techniques would have made it impossible to achieve reliable results. Already the 10 tests are supposed to be the maximum possible in one setting.

\section{Generalizability}

The methods of examination evaluated to show sufficient agreement were very efficient and can be generalized. Based on the results, the clinical examination of a supposed SIJ dysfunction can be performed reliably using the gluteal irritation of muscles with provocation in two planes in combination with the $4 \mathrm{P}$ (i.e., femur-thrust) test. In cases where these three do not have the same positive answer, they can nevertheless be used in a set with two additional tests (FAbER and Gaenslen tests) in the model " 3 out of 5 positive pain-provocation tests."

Regarding the results, there was an excellent reliability for the gluteal irritation point in combination with pain provocation in two planes. The consistent data of all pain provocation tests for the SIJ fit nicely. The study terminates with a very robust observation.
Interpretation and recommendation

This study shows that including the traditionally used irritation points (or zones) in the gluteal muscles with pain provocation according to the possible directions within the SIJ (nutation or counternutation) within a set of five tests is highly reliable and will lead to good results for the diagnostic determination of a neutral function or a unilateral dysfunction of the SIJ.

\section{Corresponding address}

\section{W. von Heymann}

Orthopädische Praxis

Mendestr. 7, 28203 Bremen, Germany

heymann@cosit.de

Funding. The study was funded by the Physicians' Association for Manual Therapy on Spine and Extremities (DGMM-MWE); the raters and the tested subjects received no refunding for participation

\section{Compliance with ethical guidelines}

Conflict of interest. W. von Heymann, H. Moll, and G. Rauch declare that they have no competing interests.

All procedures performed in studies involving human participants were in accordance with the ethical standards of the institutional and/or national research committee and with the 1964 Helsinki declaration and its later amendments or comparable ethical standards (approved by the ethics commission of the Chamber of Physicians of Baden-Wuerttemberg under the number F-2016-037). Informed consent was obtained from all individual participants included in the study. Additional informed consent was obtained from all individual participants from whom identifying information is included in this article.

Open Access. This article is distributed under the terms of the Creative Commons Attribution 4.0 International License (http://creativecommons.org/licenses/by/ 4.0/), which permits unrestricted use, distribution, and reproduction in any medium, provided you give appropriate credit to the original author(s) and the source, provide a link to the Creative Commons license, and indicate if changes were made.

\section{References}

1. Beales DJ, O'Sullivan PB, Briffa NK (2009) Motor control patterns during an active straight leg raise in chronic pelvic girdle pain subjects. Spine (Phila Pa 1976) 34:861-870

2. Berthelot JM, Labat JJ, Le GoffB, Gouin F, Maugars Y (2006) Provocative sacroiliac joint maneuvers and sacroiliac joint block are unreliable for diagnosing sacroiliac joint pain. Joint Bone Spine 73:17-23

3. Böhni U (2015b) Lumbosakraler Übergang und Beckenring. In: Böhni U, Lauper $\mathrm{M}$, Locher $\mathrm{H}$ (eds) Manuelle Medizin 1. Thieme, Stuttgart, pp 544-586

4. Böhni U, Locher H (2015a) Neurophysiologische Grundlagen der segmentalen Dysfunktion. In: Böhni U, Lauper M, Locher H (eds) Manuelle Medizin 1. Thieme, Stuttgart, pp 186-191

5. Böhni U, Lauper M, Locher H (2012) Manuelle Medizin 2. Diagnostische und therapeutische Techniken praktisch anwenden. Thieme, Stuttgart, pp 384-395

6. Bowen V, Cassidy JD (1981) Macroscopic and microscopic anatomy of the sacroiliac joint from embryonic life to the eighth decade. Spine (Phila Pa 1976) 6:620-628

7. Cohen J (1960) A coefficient of agreement for nominal scales. Educ Psychol Meas 20:37-46

8. Dreyfuss P, Michaelsen M et al (1996) The value of medical history and physical examination in diagnosing sacroiliac joint pain. Spine (Phila Pa 1976) 21:2594-2602

9. Fortin J, Aprill C, Ponthieux B et al (1994) Sacroiliac joint: pain referral maps upon applying a new injection/arthrography technique. Part II: clinical evaluation. Spine 19:1483-1489

10. Fortin JD, Tolchin RB (2003) Sacroiliac arthrograms and post-arthrography computerized tomography. Pain Physician 6:287-290

11. Fortin JD, Kissling RO, O'Connor BL, Vilensky JA (1999) Sacroiliac joint innervation and pain. Am J Orthop (Belle Mead, NJ) 28:687-690

12. Grob KR, Neuhuber WL, Kissling RO (1995) Innervation of the sacroiliac joint of the human. ZRheumatol 54:117-122

13. Hancock MJ, Maher CG et al (2007) Systematic review of tests to identify the disc, SIJ or facet joint as the source of low back pain. Eur Spine J $16: 1539-1550$

14. Ikeda R (1991) Innervation of the sacroiliac joint. Macroscopical and histological studies. Nippon lka Daigaku Zasshi 58:587-596

15. Klein P, Sommerfeld P (2004) Biomechanik der menschlichen Gelenke - Grundlagen, Becken, untere Extremität. Urban \& Fischer, München, pp 142-168

16. Landis JR, Koch GG (1977) The measurement of observer agreement for categorical data. Biometrics 33:159-174

17. Laslett M (2008) Evidence-based diagnosis and treatment of the painful sacroiliac joint. J Man Manip Ther 16:142-152

18. Laslett M, Aprill CN et al (2005) Diagnosis of sacroiliac joint pain: validity of individual provocation tests and composites of tests. Man Ther 10:207-218

19. Laslett M, Young SB et al (2003) Diagnosing painful sacroiliac joints: a validity study of a mcKenzie evaluation and sacroiliac provocation tests. Aust J Physiother 49:89-97

20. Maigne JY, Aivaliklis A, Pfefer F (1996) Results of sacroiliac joint double block and value of sacroiliac pain provocation tests in 54 patients with low back pain. Spine (Phila Pa 1976) 21:1889-1892

21. McCombe PF, Fairbank JC, Cockersole BC et al (1989) 1989 Volvo Award in clinical sciences. Reproducibility of physical signs in low-back pain. Spine (Phila Pa 1976) 14:908-918

22. Meijne W, van Neerbos Ketal (1999) Intraexaminer and interexaminer reliability of the Gillet test. JManipulative Physiol Ther 22:4-9 
23. Mense S (2011) Differences between myofascial tripper-points and tender-points. Schmerz 25:93-103

24. Patel N, Gross A, Brown L et al (2012) A randomized, placebocontrolled study to assess the efficacy of lateral branch neurotomy for chronic sacroiliac joint pain. Pain Med 13:383-398

25. Potter N, Rothstein J (1985) Intertester reliability for selected clinical tests of the sacroiliacjoint. Phys Ther 65:1671-1675

26. Robinson HS, Brox Jl et al (2007) The reliability of selected motion- and pain provocation tests for the sacroiliacjoint. Man Ther 12:72-79

27. Solonen KA (1957) The sacroiliac joint in the light of anatomical, roentgenological and clinical studies. Acta Orthop Scand 28(Suppl):1-127

28. Stecco C (2015) Chapter 3: deep fasciae. In: Functional atlas of the human fascial system. Churchill Livingstone, Edinburgh, pp 51-102

29. Stecco C, Pavan P, Pachera P, DeCaro R, Natali A (2014) Investigations of the mechanical properties of the human crural fascia and their possible clinical implications. Surg Radiol Anat 36:25-32

30. Sturesson B, Uden A, Vleeming A (2000a) A radiostereometric analysis of movements of the sacroiliac joints during the standing hip flexion test. Spine (Phila Pa 1976) 25:364-368

31. Sturesson B, Uden A, Vleeming A (2000b) A radiostereometric analysis of the movements of the sacroiliac joints in the reciprocal straddle position. Spine (Phila Pa 1976) 25:214-217

32. Szadek KM, van der Wurff P et al (2009) Diagnostic validity of criteria for sacroiliac joint pain: a systematic review. J Pain 10:354-368

33. Szadek KM, Hoogland PV, Zuurmond WW et al (2008) Nociceptive nerve fibers in the sacroiliac joint in humans. Reg Anesth Pain Med 33:36-43

34. Szadek KM, Hoogland PV, Zuurmond WW et al (2010) Possible nociceptive structures in the sacroiliac joint cartilage: an immunohistochemical study. Clin Anat 23:192-198

35. Visser LH, Nijssen PG et al (2013a) Sciaticalike symptoms and the sacroiliac joint: clinical features and differential diagnosis. Eur Spine J 22:1657-1664

36. Visser LH, Woudenberg NP et al (2013b) Treatment of the sacroiliac joint in patients with leg pain: a randomized-controlled trial. Eur Spine J 22:2310-2317

37. Vleeming A, Schuenke MD et al (2012) The sacroiliac joint: an overview of its anatomy, function and potential clinical implications. J Anat 221:537-567

38. Vleeming A, Stoeckart R (2007) The role of the pelvic girdle in coupling the spine and the legs: a cinical-anatomical perspective on pelvic stability. In: Vleeming A, Mooney V, Stoeckart R (eds) Movement, stability and lumbopelvic pain: integration and research. Churchill Livingstone, Edinburgh, pp 113-137

39. Vleeming $A$, Albert $H B$, Ostgaard $\mathrm{HC}$ et al (2008) European guidelines for the diagnosis and treatment of pelvic girdle pain. Eur Spine J 17:794-819

40. van derWurffP,BuijsEJ,Groen GJ (2006) A multitest regimen of pain provocation tests as an aid to reduce unnecessary minimally invasive sacroiliac joint procedures. Arch Phys Med Rehabil 87:10-14

\section{Aktuelle Empfehlungen aus dem Springer-Verlag}

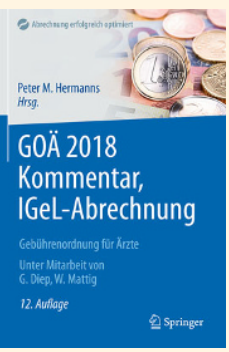

\section{GOÄ 2018 Kommentar, IGeL-Abrechnung}

Hermanns, Peter M. (Hrsg.)

12. Auflage, XXVI, 910 Seiten, 79,99 Euro, ISBN 978-3-662-56493-6

- Kommentar für Praxis und Klinik

- Mit Auslegungshinweisen der BÄK, IGeL-Hinweisen und Abrechungsbeispielen

- Amtliche Gebührenordnung - Ausschlüsse - Analoge Bewertungen -

Abrechnungstipps

- Mit aktuellen Gerichtsurteilen

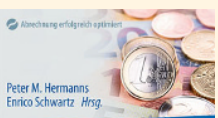

UV-G0Ä 2018

Kommentar
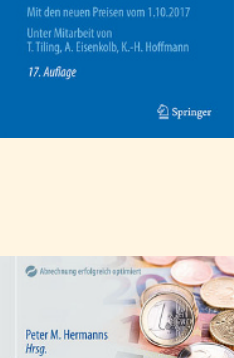

EBM 2018

Kommentar

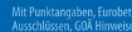

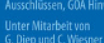

s. alinge

פ̂stringer

\section{UV-GOÄ 2018 Kommentar}

Hermanns, Peter M., Schwartz, Enrico (Hrsg.)

17. Auflage, XXIV, 728 Seiten, 69,99 Euro, ISBN 978-3-662-56482-0

- Zuständigkeit der UV-Träger auf einen Blick

- Alle praxisrelevanten Kommentierungen, inklusive aktuelle Gerichtsurteile

- Mit Abrechnung bei Arbeitsunfällen und Berufskrankheiten

Korrekt, rechtssicher, vollständig

\section{EBM 2018 Kommentar}

Hermanns, Peter M. (Hrsg.)

8. Auflage, XXII, 902 Seiten, 79,99 Euro, ISBN 978-3-662-56487-5

- Vollständige Leistungslegenden mit Bewertungen

- Ausschlüsse

- Wer darf was wann im EBM abrechnen

- Praktische Abrechnungstipps und -beispiele mit Auslegungshinweisen, Beschlüssen, Richtlinien, Texten, u.a. von KBV und regionalen KVen, G-BA, Sozialgesetzbuch (SGB) 